\title{
Finalização da Licença-Maternidade: Desafios para a Manutenção do Aleitamento Materno Exclusivo por Trabalhadoras Formais
}

\author{
End of Maternity Leave: Challenges to Maintaining Exclusive Breastfeeding \\ by Formal Working Women
}

\author{
Jordana Muniz Silva ${ }^{1}$ \\ Kariane Gomes Cezario Roscoche ${ }^{2}$ \\ Iculmari Coutinho Sampa ${ }^{1}$ \\ Ana Keile Souza Rodrigues ${ }^{1}$ \\ Francisca Weslla Oliveira da Silva ${ }^{1}$ \\ Albertina Antonielly Sydney de Sousa ${ }^{3}$
}

\section{RESUMO}

Objetivo: Descrever a vivência da manutenção da prática do aleitamento materno exclusivo segundo a percepção de mães, quando do retorno ao trabalho. Metodologia: Trata-se de estudo exploratório-descritivo, qualitativo, realizado em uma Instituição de Ensino Superior de Fortaleza-Ceará com nove mulheres, selecionadas por meio do método de amostragem bola de neve, que vivenciaram ou estavam vivenciando a experiência do aleitamento enquanto trabalhadoras formais. Os dados foram coletados em novembro de 2016, por meio de entrevista semiestruturada e analisados pela técnica de análise temática, proposta por Minayo. Resultados: Da análise das entrevistas emergiram três categorias que abrangeram o "Conhecimento das mães sobre a amamentação"; "Sentimentos maternos no retorno ao trabalho" e "Dificuldades para manutenção da lactação exclusiva no retorno ao trabalho". Conclusão: As mães mostraram conhecimento sobre o aleitamento exclusivo alinhado às recomendações dos organismos de saúde, sendo grande parte das informações fornecida antes da alta da maternidade pelos profissionais de saúde. O retorno ao trabalho se apresentou como fator estressor para a manutenção do aleitamento exclusivo devido à separação física da criança, da longa distância entre o local de trabalho e a residência, o não cumprimento do horário da amamentação pelo empregador, as longas jornadas de trabalho e a falta de espaço adequado para a ordenha ou amamentação. Torna-se necessário que sejam desenvolvidas estratégias intersetoriais para garantir que as mães trabalhadoras que optarem pela amamentação dos filhos, principalmente em caráter exclusivo, tenham esta prática facilitada.

\section{DESCRITORES}

Aleitamento Materno. Licença Parental. Mulheres Trabalhadoras. Enfermagem.

\begin{abstract}
Objective: To describe the experience of maintaining the exclusive breastfeeding practice according to the mothers' perception, when they return to work. Method: This is an exploratory-descriptive, qualitative study, carried out in a Higher Education Institution in Fortaleza-Ceará with nine women selected through the snowball method, who experienced or were experiencing breastfeeding practice as formal workers. Data were collected in November 2016 through semi-structured interviews and analyzed using the Thematic Analysis technique proposed by Minayo. Results: Three categories emerged from the interviews' analysis: Mothers' knowledge about exclusive breastfeeding; Maternal feelings on returning to work and Difficulties in maintaining exclusive lactation on returning to work. Conclusion: Mothers' knowledge about exclusive breastfeeding was according to the health agencies' recommendations and most of the information was provided by health professionals, before the discharge from maternity. Returning to work was perceived by the women as a stress factor for maintaining exclusive breastfeeding due to the child's physical separation, long distance between the workplace and the home, the employer's failure to comply with the breastfeeding schedule, long working journey and no adequate space for milking or breastfeeding. It is necessary to develop intersectoral strategies to ensure that working mothers who choose to breastfeed their children, especially on an exclusive way, have this practice facilitated.
\end{abstract}

\section{DESCRIPTORS}

Breastfeeding. Parental Leave. Working Women. Nursing.

${ }^{1}$ Enfermeira graduada pelo Centro Universitário Estácio do Ceará, Fortaleza, Ceará, Brasil.

Enfermeira em Saúde Mental e Psiquiatria. Doutora em Enfermagem pela Universidade Federal do Ceará. Docente da Universidade Federal do Paraná, Curitiba, PR, Brasil.

${ }^{3}$ Enfermeira do Trabalho. Doutora em Cuidados Clínicos em Enfermagem e Saúde pela Universidade Estadual do Ceará. Docente visitante da Universidade da Integração Internacional da Lusofonia Afro-Brasileira (UNILAB), Redenção, CE, Brasil. 


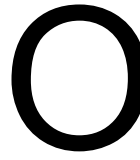
aleitamento materno (AM) consiste no ato da mãe oferecer o leite do peito ao bebê e, segundo a Organização Pan-Americana da Saúde/Organização Mundial da Saúde (OPAS/OMS), recomenda-se iniciá-lo na primeira hora de vida e de forma exclusiva de alimentação até os seis meses de idade e, de maneira complementar, até os dois anos ${ }^{1}$.

Classifica-se como aleitamento materno exclusivo (AME) quando a criança recebe somente o leite materno, direto da mama ou ordenhado, ou leite humano de outra fonte, sem outros líquidos ou sólidos, com exceção de gotas ou xaropes contendo vitaminas, sais de reidratação oral, suplementos minerais ou medicamentos, conforme prescrição médica² .

O reforço à adoção da prática do AME se justifica pelo fato de que a oferta de outros alimentos antes dos seis meses, além de ser desnecessária, pode ser prejudicial à saúde infantil, pois eleva o risco do desenvolvimento de doenças, podendo interferir na absorção de importantes nutrientes presentes no leite materno; além disso, o sistema gastrointestinal do bebê ainda está imaturo para receber outros tipos de alimento1.

As vantagens do AME são mais efetivas do que o AM somente até três ou quatro meses, seguido de aleitamento misto. Dentre os seus benefícios à saúde infantil, citam-se os de natureza nutricional, gastrointestinal e imunológica, uma vez que o leite materno apresenta constituição rica em água, vitaminas, minerais, proteínas, lipídios e anticorpos. Nesse escopo, destacam-se as facilidades de digestão do leite e da absorção de seus nutrientes e prevenção de doenças agudas, como a diarreia, as pneumonias e otites e, ou- tras, como a asma, o diabetes e a obesidade. Os desenvolvimentos físico, intelectual e emocional/psicológico, obtidos em longo prazo, refletem-se no processo de sucção, deglutição e mastigação efetivas, do alinhamento correto dos dentes, do estímulo ao desenvolvimento cognitivo e a formação do vínculo afetivo entre a mãe e o bebê $\hat{e}^{1,3}$.

Em relação aos benefícios maternos, a amamentação minimiza a incidência dos cânceres de mama e de colo do útero; acelera a involução uterina no pós-parto, diminuindo as eliminações sanguíneas e evitando a anemia; pode funcionar como método contraceptivo natural durante os seis primeiros meses, desde que a mãe esteja amamentando exclusivamente, em livre demanda e ainda não tenha menstruado; ajuda na perda do peso obtido na gestação e reduz a chance de desenvolvimento de hipertensão, do diabetes mellitus tipo 2, da obesidade e do colesterol elevado. Em âmbito subjetivo, o aleitamento pode reforçar a autoestima e elevar a percepção da autoeficácia materna ${ }^{1,3}$.

Em relação ao impacto positivo sobre os indicadores de saúde, estima-se que a prática do AME possa prevenir, anualmente, a morte de cerca de um milhão de crianças por diarreia e infecções ${ }^{4}$. No entanto, apesar de todos os benefícios, incentivos e suporte à sua prática, o desmame precoce ainda se apresenta como um problema de saúde pública mundial e no Brasil, apesar da prevalência de $54 \%$ AME ser classificada com o indicador "bom" (entre 50 a 89\%), ainda apresenta desigualdades regionais. Todas as regiões brasileiras apresentaram indicadores com valores positivos entre 55 e 59\% e a Região Nordeste apresentou a menor prevalência de AME (39\%), exibindo indicador "razoável"5. 
Define-se o desmame precoce como a introdução de qualquer tipo de alimento na dieta de uma criança que, até então, se encontrava em regime de $\mathrm{AME}$, independente dos motivos que o provocaram, antes do período de seis meses $^{2}$. Apesar das recomendações, a prática do $\mathrm{AM}$, exclusivo ou não, envolve um complexo contexto histórico, cultural e socialmente construído e depende de fatores relacionados tanto à mãe quanto ao bebê. Ao se considerar o desmame precoce, deve-se percebê-lo como um processo e não somente a interrupção abrupta do $\mathrm{AME}^{6}$; desta forma, fala-se em "período de desmame", que compreende desde a introdução do novo alimento até a supressão completa do $\mathrm{AM}^{2}$.

Dentre os fatores contribuintes para o desmame precoce relacionados ao lactente, elencam-se o déficit na sucção-deglutição, a prematuridade, a hospitalização e uso de bicos artificiais ${ }^{4,7,8}$. Em outra vertente, verificam-se como notáveis influenciadores maternos a dinâmica da produção láctea combinada com a posição e com a pega incorreta do seio pelo bebê; extremos de idade materna; estados de fragilidade emocional; falta de apoio familiare inserção no mercado de trabalho associada ao curto tempo da licença maternidade ${ }^{9,10}$.

Esse último quesito desponta dentre os que levam a decisão materna de interromper o aleitamento exclusivo. Devido as mudanças relacionadas aos processos de industrialização, urbanização, modernização e a mudança dos papeis femininos na sociedade, principalmente, o ganho de espaço no mercado de trabalho, as dificuldades em manter o AM se tornaram frequentes entre as mães trabalhadoras de todo o mundo ${ }^{9,11-13}$. No Brasil, dispositivos legais garantem a licença maternidade, sem o prejuízo do emprego e do salário, com duração de 120 dias. Quando do retorno ao trabalho, assegura-se à nutriz o direito a dois descansos especiais para amamentar, de meia hora a cada uma, durante a jornada de trabalho, até o $6^{\circ}$ mês de vida do bebê, diferentes dos intervalos normais para o repouso e a alimentação; além da disposição de locais adequados para os cuidados com o lactente ${ }^{3}$.

Mesmo perante os esforços envidados para manter a prática do aleitamento entre as mães trabalhadoras, muitas delas ainda têm dificuldade de amamentar a criança durante a jornada de trabalho, principalmente em grandes centros urbanos, onde o transporte é ineficiente e/ou é muito grande a distância entre o local de trabalho e o local de permanência da criança e, também, quando seus direitos legais não são salvaguardados ${ }^{11,14}$.

Logo, percebe-se que no complexo contexto que envolve o processo do desmame precoce, as trabalhadoras formais apontam como um segmento vulnerável a esta condição. Apesar da decisão de amamentar ou não ser uma escolha materna individual, deve-se estimular o aleitamento o maior tempo possível, dentro da realidade de vida da mãe e do bebê ${ }^{6}$. Nesse âmbito, os profissionais de saúde podem atuar de forma positiva na manutenção do aleitamento, desenvolvendo práticas adequadas de cuidado, uma vez que compreendem os processos psicofisiológicos, socioculturais e econômicos que o envolve ${ }^{15}$.

O manejo das dificuldades com o intuito de promover e apoiar o AM exige um conjunto de habilidades técnicas e relacionais, norteado por uma escuta sensível capaz de captar as particularidades da nutriz. Desta 
forma, ressalta-se a necessidade do preparo adequado dos profissionais de saúde, uma vez que a resolução de questões práticas relacionadas às orientações, pode refletir diretamente no sucesso das taxas de $\mathrm{AME}^{9,15,16}$.

Dentre os profissionais habilitados para acompanhar a mãe desde a gestação até o puerpério, o enfermeiro se destaca ao apresentar conhecimentos, habilidades e atitudes que contribuem para o manejo clínico eficaz da amamentação, apoiando esta prática e enfrentando o desmame precoce, principalmente, por meio de orientações que reforcem o conhecimento sobre o aleitamento e estimulem a autoeficácia materna ${ }^{17}$.

No que tange à particularidade de nutrizes trabalhadoras, é necessário o reconhecimento de suas dificuldades, sob diferentes pontos de vista e contextos de vida, para conciliar o retorno à rotina laboral com a manutenção do aleitamento. Ao se identificar essas necessidades, orienta-se para que 0 enfermeiro possa definir, juntamente com a mãe, estratégias direcionadas para a promoção e a proteção da saúde no âmbito do AME.

Ante o exposto, objetivou-se descrever a vivência da manutenção da prática do aleitamento materno exclusivo segundo a percepção de mães no retorno ao trabalho.

\section{METODOLOGIA}

Tratou-se de um estudo exploratório-descritivo, qualitativo, realizado em uma Instituição de Ensino Superior (IES) no Município de Fortaleza-Ceará, com nove mulheres (dentre estudantes, docentes e colaboradoras da IES) que vivenciaram ou estavam vivenciando a experiência do aleitamento materno exclusivo enquanto trabalhadoras formais.

Para a seleção das participantes estabeleceram-se como critérios de inclusão: idade igual ou superior a 18 anos completos; ter trabalhado ou estar trabalhando formalmente durante o período de seis meses, preconizado para a amamentação exclusiva. Para a captação dos sujeitos, adotou-se a técnica metodológica "Bola de Neve" (Snowball), tipo de amostragem não probabilística onde os participantes iniciais de um estudo (denominados "sementes") indicam novos participantes que, por sua vez, indicam novos participantes e assim sucessivamente, até que seja alcançado o ponto de saturação, onde os novos entrevistados passam a repetir os conteúdos já obtidos em entrevistas anteriores, sem acrescentar novas informações relevantes à pesquisa ${ }^{18}$.

A primeira participante foi selecionada intencionalmente pelas pesquisadoras por atender os critérios de inclusão e, a partir dela, outras possíveis participantes foram indicadas. O contato com as potenciais participantes da pesquisa foi realizado mediante abordagem direta na IES ou por ligação telefônica e, em caso de aceite do convite, agendava-se um encontro em dia e horário determinados pela participante.

A coleta de dados ocorreu em novembro de 2016, por meio de entrevista semiestruturada composta por questões acerca dos dados do perfil das participantes e do conhecimento, sentimentos, dificuldades e estratégias para a manutenção do AME pelas mães, após o retorno ao trabalho. As entrevistas foram realizadas individualmente em locais reservados e escolhidos pelas participantes (no próprio domicílio ou na IES); gravadas, após 
autorização prévia, por meio de gravador de áudio do aparelho celular do pesquisador.

As entrevistas tiveram média de vinte minutos e seus áudios foram transcritos na íntegra e organizados no software de texto Microsoft Word ${ }^{\circledR}$. O conteúdo transcrito foi analisado segundo a técnica de análise temática proposta por Minayo ${ }^{19}$, definida como um conjunto de técnicas de análise das comunicações que utiliza procedimentos sistemáticos e objetivos de descrição do conteúdo das mensagens. Esta técnica se compõe de três etapas: (1) pré-análise, que consiste na organização do corpus da análise, leitura flutuante do material e constituição e formulação de hipóteses e objetivos; (2) exploração do material por meio da identificação/definição de categorias empíricas emergentes; e (3) tratamento e interpretação dos resultados, que consiste no destaque das informações para análise, culminando nas interpretações inferenciais com base na literatura pertinente.

O estudo foi aprovado pelo Comitê de Ética em Pesquisa do Centro Universitário Estácio do Ceará (Parecer $\left.n^{\circ} 1.818 .849\right)$ e respeitou-se os aspectos ético-legais preconizados pela Resolução 466/12 do Conselho Nacional de Saúde, que versa sobre a pesquisa envolvendo seres humanos. As participantes foram informadas sobre os objetivos da pesquisa e consentiram sua participação mediante assinatura do Termo de Consentimento Livre e Esclarecido, fornecido em duas vias: uma para o participante e outra para o pesquisador. Para manter o anonimato, as participantes foram identificadas com a letra "M", seguida de numeração (M1, M2, M3...), à medida que se realizavam as entrevistas.

\section{RESULTADOS}

Participaram do estudo nove mulheres com idade entre 23 e 36 anos. Quanto ao estado civil, oito eram casadas e uma solteira. A maioria das mulheres (sete) tinha apenas um filho; e as demais, dois e três filhos. Quanto à crença religiosa, sete eram católicas e duas, evangélicas. Em relação à escolaridade, uma era pós-graduada, quatro possuíam formação de nível superior completo e duas incompleto e duas tinham o segundo grau completo. Quanto à atividade profissional, destacaram-se como ocupações: três vendedoras, duas enfermeiras, duas técnicas de enfermagem, uma design de móveis e uma recepcionista, todas trabalhando em empresas privadas, conforme a Consolidação das Leis Trabalhistas e com carga horária variando entre 30 e 40 horas semanais. A renda familiar variou entre um e meio a oito salários.

A partir da análise das entrevistas, emergiram três categorias: Conhecimento das mães sobre a amamentação; Sentimentos maternos no retorno ao trabalho; Dificuldades para manutenção da lactação exclusiva no retorno ao trabalho, as quais são apresentadas a seguir.

Conhecimento das mães sobre a amamentação

Os relatos das mães evidenciaram que elas tinham conhecimento satisfatório sobre o AM, o qual foi oriundo principalmente de orientações dos profissionais de saúde, após o parto. Apenas uma mãe relatou não ter recebido informações em qualquer momento. As orientações versaram principalmente quanto ao tempo ideal de manutenção 
do aleitamento, pontos específicos da amamentação como a pega, os intervalos da oferta e os cuidados com a alimentação da nutriz. Em uma das falas, ficou evidente a participação do enfermeiro:

"Ao sair de alta hospitalar, após o parto, recebi orientações da enfermeira sobre como colocar o bebê para sugar e as frequências das mamadas e a importância de alternar as mamas. Amamentação exclusiva até seis meses" (M7).

"Amamentar até no mínimo seis meses. Isso foi passado ao sair da maternidade" (M5).

"Sim! Cuidados com a alimentação, pois tudo reflete na saúde do bebê, evitando comer frituras e refrigerante" (M9).

Outro aspecto importante do conhecimento das mães sobre o AM se relacionou aos benefícios concedidos pela prática tanto no que diz respeito às características do leite materno quanto ao reforço do vínculo materno-infantil, observado nos relatos seguintes:

"O leite materno contém as proteínas e vitaminas necessárias para o bebê crescer saudável" (M9).

"O leite materno é muito importante para o bebê porque tem vitaminas e proteínas necessárias para o bebê" (M2).

"O aleitamento materno é muito importante para o bebê devido aos seus nutrientes e também pelo laço afetivo entre mãe e bebê" (M3).

"A importância é sem medidas para a saúde do meu filho, para o seu crescimento. $E$ neste momento é que me sinto mais próxima" (M5).
Sentimentos maternos no retorno ao trabalho

As falas que marcam esta categoria revelam sentimentos de impotência, culpa, tristeza e frustração concernentes à manutenção do AME quando do retorno ao trabalho. A separação física da criança também se revelou como um fator de inquietação por parte das mães, somando-se a um contexto de interferências negativas sobre a autoestima e a percepção da autoeficácia materna. Os relatos a seguir expressam tais aflições:

"Ao retornar ao trabalho, senti-me impotente ao ter que deixá-lo, mesmo que com minha mãe, bem como ter que iniciar outros alimentos" (M7).

"Senti-me vazia e culpada, me preocupei no meu retorno ao trabalho, na alimentação dele, sua saúde, com quem ficar" (M5).

"Dificuldade, pois tinha que passar a semana em outra cidade. Sentimento de incapacidade" (M1).

"Muito triste, pois meu filho teve que tomar leite e completar com mama, no dia que estou em casa" (M4).

No distanciamento do filho, imposto pelo retorno ao trabalho, as mães se viram confrontadas com a nova realidade referente à maneira de como se relacionar com o bebê e suprir suas necessidades. As falas revelaram sentimentos de saudade e vazio, decorrentes da diminuição do contato físico, anteriormente mais intenso, além do medo de que a produção do leite ficasse prejudicada pela diminuição da frequência das mamadas:

"Péssima! Senti medo que meu leite diminuísse pelas quantidades de mamadas, dificuldade e angústia para tentar estocar leite materno e continuar o aleitamento materno 
exclusivo. Saudade por ter que me afastar dele por tanto tempo" (M3).

"Senti-me vazia e com falta dele, pois estava acostumada em estar sempre com ele"(M2). "Pensei em sair do trabalho para ficar só com ele, até completar um ano" (M4).

Dificuldades para manutenção da lactação exclusiva no retorno ao trabalho

Nesta categoria, identificaram-se nos relatos maternos elementos relacionados ao manejo das demandas de trabalho e o AME. Apesar de a amamentação ter sido mantida até os seis meses de vida do bebê, muitos obstáculos foram mencionados como impeditivos à continuidade da prática de forma exclusiva. Dificuldades como grande distância do trabalho para o lar; carga horária laboral elevada; desrespeito ao direito de intervalo para amamentar; e divergências dos locais de trabalho quanto à adequação da estrutura física para a prática ou reforço ao AME, foram mencionados como limitadores em longo prazo:

"Quando ele fez seis meses, tive que voltar para Fortaleza. Ele passava quatro dias lá no interior e eu vinha pra cá estudar e dar alguns plantões à noite. Eu ordenhava e congelava o leite, mas no final não conseguia dar o retorno a ele" (M1).

"A ansiedade para voltar para casa e a distância entre meu trabalho e o meu lar"(M2). "Eu não saía uma hora antes, que é justo por lei, pois a empresa não me permitia" (M5). "Dificuldade maior no trabalho é em relação à falta de tempo para desmame, pois a carga do trabalho exige muito da gente. (...) Mas onde trabalho existe posto de coleta, banco de leite e posso desmamar e armazenar, quando há condições, e levar para casa" (M3).

"Não tinha tempo, o trabalho era longe demais e só tinha de uma a uma hora e meia de intervalo, e o trabalho não oferece local para ordenhar ou armazenar o leite" (M6).

Além dessas dificuldades, algumas mães também relataram complicações relacionadas à problemas mamários, como mastite e fissuras, como condições desconfortáveis e que poderiam impactar negativamente na manutenção do AME:

"A enfermeira e a médica, elas disseram que eu ia ter que fazer um tratamento, que ia virar mastite" (M8).

"A área do meu peito ficou toda vermelha (...) senti calafrios (...) meu peito estava quente, pegando fogo. Pesquisei na internet, acho que é isso: mastite mamária" (M6).

"Durante a minha gestação preparei poucas vezes o seio para evitar fissuras, mas mesmo com tanta orientação, tive fissuras que duraram um mês para cicatrizar. Fiz desmame normal para garantir que o leite não diminuísse" (M3).

\section{DISCUSSÃO}

De acordo com os relatos, ficou evidente que o conhecimento de grande parte das mães estava alinhado às recomendações propostas pelas organizações de saúde nacionais e internacionais, que orientam a duração do AME por seis meses ${ }^{1-3}$. No contexto dos relatos, tal fator foi atribuído à atuação dos profissionais durante o período de estadia das mães na maternidade, ressaltando a importância do reforço às orientações antes da alta.

O período do pós-parto imediato até a 
saída da mãe da maternidade se constitui em um momento oportuno para reforçar orientações e também identificar possíveis dúvidas ou dificuldades concernentes ao aleitamento materno ${ }^{15}$. No entanto, salienta-se que os apoios informacional e emocional devem ser prestados durante todo o ciclo gravídico-puerperal, no qual a consulta de pré-natal se mostra como um dos principais espaços para a construção de um vínculo significativo entre o profissional e a mãe.

O processo de acompanhamento da mãe e do bebê, desde a concepção ao nascimento, destaca a figura do enfermeiro como mediador, prestando cuidado clínico de enfermagem, em uma perspectiva humanizada e com suporte técnico-científico. Orientações referentes aos cuidados gerais com o RN e, mais especificamente, relacionados ao AM como a pega e a posição correta para amamentar, ordenha das mamas e sua frequência, bem como aos benefícios da amamentação para a mãe e para o bebê, são fundamentais para reforçar a sensação de segurança e autoconfiança das mães durante o aleitamento.

Nesta perspectiva, o enfermeiro pode se valer de tecnologias de cuidado em saúde de diversas naturezas, destacando-se as leves, como a escuta ativa, o aconselhamento e o estabelecimento de contato pele-a-pele entre a mãe e o bebê; assim como as duras, por meio do uso de vídeos, folhetos e cartilhas educativas. É importante, no entanto, que o uso desses recursos esteja alinhando às singularidades de cada mãe, para que possam ser percebidos e incorporados à maternagem como um todo ${ }^{17,20-21 .}$

Estratégias diversificadas de cuidado aliadas à competência profissional podem influenciar, sobremaneira, na decisão das mães em amamentar e manter a lactação, principalmente de maneira exclusiva. Desta forma, é importante dar condições concretas para que mães e bebês vivenciem esse processo de forma prazerosa e eficiente, além de considerar as dificuldades e os desejos da puérpera sobre a decisão de amamentar ou de não amamentar ${ }^{6,11,22}$.

No contexto das informações prestadas sobre o aleitamento, um aspecto interessante emergiu de uma das falas, mencionando acerca da interferência da alimentação da nutriz sobre a qualidade do leite materno. Este achado corrobora outros estudos sobre crenças e tabus alimentares que apontam que alguns alimentos não devem ser consumidos durante a amamentação ${ }^{23,24}$.

Dentre os diversos elementos que se relacionam direta ou indiretamente com a lactação, a dieta materna, como fonte de nutrientes para a produção adequada de leite, pode ser influenciada por questões econômicas, sociais e culturais. Dentre as questões culturais, os tabus ou restrições alimentares, nem sempre justificáveis do ponto de vista biológico, podem fazer com que a lactante se prive de nutrientes importantes para o seu sustento e, consequentemente, para a produção de leite ${ }^{23}$.

Como orientação correta, recomenda-se à lactante que a ingestão alimentar deve ser equilibrada, com aporte energético suficiente para a produção de leite e que proporcione uma perda do peso adquirido durante a gestação, na ordem de 0,5 a 1 kg ao mês ${ }^{25}$. Desta forma, não são recomendadas dietas ou restrições alimentares, tendo em vista que a associação de certos alimentos às respostas 
dadas pelo bebê, como a manifestação de cólicas, ainda é cientificamente controversa e pode contribuir para o desmame precoce.

Desta forma, o ideal é que a mãe tenha uma alimentação o menos industrializada possível, faça uma boa ingestão de água e identifique os alimentos que, possivelmente, possam evidenciar desconforto ao bebê, reportando-se a um profissional de saúde para maiores orientações. Nessa perspectiva, pensar na alimentação da nutriz implica conhecer todos os aspectos que interferem em suas escolhas alimentares, entendendo seus hábitos e crenças, para que o cuidado prestado seja adequado ao contexto no qual ela se insere ${ }^{24}$.

Outros dois aspectos mencionados pelas participantes de nosso estudo acerca do conhecimento sobre a amamentação dizem respeito aos benefícios relacionados à saúde da criança e ao reforço ao vínculo afetivo entre a mãe e o filho. Tais achados corroboram outros estudos, apontando-os como protetores contra o desmame precoce ${ }^{6,11}$.

Foi ressaltado que o reflexo da AME sobre a criança é observado por índices satisfatórios no desenvolvimento cognitivo, neuropsicomotor e social e pela proteção contra doenças agudas e infecciosas, bem como doenças crônicas, em longo prazo ${ }^{1-3}$. Além das vantagens nutricionais, o aleitamento reforça a relação entre a mãe e o filho, constituindo-se em um momento afetivo íntimo e singular, refletindo sentimentos maternos de prazer, aconchego e autoconfiança e sendo considerado pela maioria das mulheres como a plenitude do exercício do papel materno ${ }^{11}$.

Outro quesito relatado na literatura como favorecedor do desmame precoce, diz respeito aos problemas mamários como fis- sura mamilar, mastite puerperal, bloqueio de ductos e abscesso mamilar ${ }^{26}$. Em nosso estudo, algumas mães sinalizaram a existência desta condição, no entanto não ficou evidente se isso interferiu na continuação do AME.

Sentimentos de angústia e frustração também emergiram das mães ao perceberem a necessidade de introduzir novos alimentos na rotina do bebê e como isso poderia influenciar em sua saúde. Tais inquietações se fundamentam, pois somente após os seis meses de vida é que o grau de tolerância do intestino e a eficiência de absorção dos nutrientes alcançam um nível satisfatório e a criança se apresenta apta a iniciar a ingesta de outros alimentos ${ }^{1-3}$. Salienta-se que essa transição deve ser orientada pelos profissionais de saúde, pois a introdução precoce dos alimentos complementares pode interferir na absorção de nutrientes pela criança, elevar o risco de alergia alimentar e de maior ocorrência de doenças crônicas na idade adulta ${ }^{27,28}$.

O regresso ao trabalho implica no afastamento entre a mãe e o filho, gerando uma conjuntura aflitiva para a nutriz, mesmo que tenha um ambiente apropriado e pessoas confiáveis para cuidar do bebê, o que gera preocupações e receios sobre a manutenção do $\mathrm{AM}$ e a perda do vínculo afetivo com o filho ${ }^{11,29}$. Desta forma, a percepção materna sobre a satisfação das necessidades nutricionais do bebê pode ser prejudicada ao achar que seu leite está em quantidade insuficiente, julgamento que realiza pelo volume da produção e quantidade de leite extraído para acondicionamento, tal como pelo ato de choro e agitação do filho durante a amamentação. Diante destas circunstâncias, é comum que as mulheres acabem por sentir a necessidade de 
complementar a alimentação do filho com leite artificial ou outros alimentos 11,27-29.

Em outra vertente, o ambiente laboral foi mencionado pelas mães como influenciadores do desmame precoce, o que corrobora os achados da literatura9 ${ }^{9,11,26}$. Grande distância entre o ambiente de trabalho e o lugar de estadia da criança; falta de estrutura adequada, como sala reservada para a amamentação ou a ordenha e a falta de material apropriado para recolhimento e a refrigeração do leite materno; longas jornadas de trabalho e desrespeito aos intervalos para amamentar são mencionados como os principais fatores para a interrupção do AME.

Salienta-se que no contexto brasileiro, existem dispositivos legais para minimizar os riscos de diminuição do aleitamento materno no período de retorno ao trabalho. A Constituição Federal, de 5 de outubro de 1988, prevê a licença maternidade, sem prejuízo do emprego e do salário, com duração de 120 dias, podendo se estender até 180 dias dependendo do regimento de trabalho. Quando do retorno ao trabalho, asseguram-se à nutriz pausas para amamentar o filho durante a jornada laboral, divididas em dois descansos especiais de meia hora cada um, até o $6^{\circ}$ mês de vida do bebê, que não se confundem com os intervalos normais para o repouso e a alimentação, além da disposição de locais adequados para os cuidados com os lactentes ${ }^{3}$.

Embora nossos resultados tenham revelado que o período de licença-maternidade menor que o período preconizado para o AME tenha sido percebido pelas mães como empecilho para efetivar a prática a contento e levado à introdução precoce de alimentos complementares, ainda assim permitiu que continuassem oferecendo o leite do peito ao bebê. Os estudos apontam que a licença-maternidade contribui para a prática do aleitamento materno exclusivo em crianças menores de seis meses de vida ${ }^{30}$ e que sua prorrogação possibilita que as mães amamentem exclusivamente por um tempo mais longo ${ }^{26}$, o que indica a importância desse benefício para as mulheres inseridas no mercado de trabalho formal.

\section{CONCLUSÃO}

O estudo revelou que as mães trabaIhadoras possuíam conhecimento alinhado às recomendações de saúde para manter o aleitamento exclusivo até os seis meses de vida do bebê. Além disso, reconheceram a prática da amamentação exclusiva como benéfica para a saúde materno-infantil, ressaltando a importância nutricional do leite materno e o reforço ao vínculo afetivo entre a mãe e o bebê. Salienta-se que grande parte das informações acerca do aleitamento foi fornecida antes da alta da maternidade.

O retorno ao trabalho ainda no processo de amamentação se apresentou como fator estressor, uma vez que despertou nas mães sentimentos negativos relacionados à separação física da criança e a impossibilidade de atender prontamente às suas demandas. Além disso, as dificuldades encontradas no contexto laboral também foram mencionadas como dificultadores da manutenção do aleitamento exclusivo, destacando-se a longa distância entre o local de trabalho e a residência, o não cumprimento do horário da amamentação pelo empregador, as longas jornadas de trabalho e a falta de espaço adequado para a ordenha ou amamentação do bebê.

Diante do exposto, percebe-se a ne- 
cessidade de se desenvolverem estratégias intersetoriais para garantir que as mães trabalhadoras que optam pela amamentação dos filhos, principalmente em caráter exclusivo, tenham esta prática facilitada. Em relação ao setor saúde, espera-se que este estudo contribua para a reflexão da participação dos profissionais, principalmente, do enfermeiro, em ações estratégicas facilitadoras do aleitamento, principalmente no contexto de retorno ao trabalho.

Em relação aos empregadores, salienta-se a necessidade de se respeitar os direitos da mãe trabalhadora, obedecendo aos dispositivos legais que as amparam a fim de que possam exercer uma maternagem sem

\section{REFERÊNCIAS}

1. Ministério da Saúde (BR). Secretaria de Atenção Primária à Saúde. Departamento de Promoção da Saúde. Guia alimentar para crianças brasileiras menores de 2 anos. Brasília: Ministério da Saúde, 2019.

2. Ministério da Saúde (BR). Secretaria de Atenção à Saúde. Departamento de Atenção Básica. Saúde da criança: nutrição infantil: aleitamento materno e alimentação complementar. Brasília: Ministério da Saúde, 2009.

3. Ministério da Saúde (BR). Secretária de atenção à saúde. Departamento de atenção básica. Cartilha para mulher trabalhadora que amamenta. Brasília: Ministério da Saúde, 2015

4. Federação Brasileira das Associações de Ginecologia e Obstetrícia. Manual de Aleitamento Materno. Federação Brasileira de Associações de Ginecologia e Obstetrícia. São Paulo: Febrasgo, 2015.

5. Nascimento JC, Silva NL, Lima MCBM, Lima MFVS, Oliveira GS. Prevalência do aleitamento materno exclusivo nas regiões brasileiras em 2015. Rev Carpe Diem. 2018;16(2):252-269.

6. Prado CVC, Fabbro MRC, Ferreira GI. Early weaning from breastfeeding from mothers' perspective: a dialogical approach. Texto Contexto - Enferm. 2016;25(2): e1580015.

7. Monteschio CAC, Gaíva MAM, Moreira MDS. O enfermeiro frente ao desmame precoce na consulta de enfermagem à criança. Rev Bras Enferm. 2015; 68(5):869-875.

8. Dadalto ECV, Rosa EM. Fatores associados ao uso de chupetas por lactentes nascidos pré-termo. Rev CEFAC. 2016; 18(3):601-612. culpa ou envolta de sentimentos negativos. Outra discussão relevante é a possibilidade de extensão da licença-maternidade para 180 dias, coincidindo com o período de duração preconizado para o aleitamento materno exclusivo.

A pesquisa teve como limitações a captação de um número de participantes reduzido, o que não permite a generalização dos achados, assim como a delimitação do estudo para apenas uma IES, o que possibilitou encontrar resultados restritos a uma realidade local. Diante disso, sugere-se a realização de estudos que permitam avaliar as conjunturas de outros cenários e com um número maior de participantes.

9. Torres, FCA, Oliveira, FFP, Messias, CM, Silva, MRB Matos, PSD; Fernandes, IM. Manutenção do aleitamento materno no retorno ao trabalho. Nursing. 2019; 22(255): 3047-3077.

10. Oliveira AKP, Melo RA, Maciel LP, Tavares AK, Amando AR, Sena CRS. Práticas e crenças populares associadas ao desmame precoce. Av Enferm. 2017; 35(3):303-312

11. Rodrigues BC, Pelloso SM, França LCR, Ichisato SMT, Higarashi IH. Aleitamento materno e desmame: um olhar sobre vivências de mães enfermeiras. Rev Rene. 2014; 15(5):832-841.

12. Robles MV, Fonseca LY, Serrano DCA, Barrios RT, Kin RG, Álvarez RCG. Comportamiento de la lactancia materna. Consultorio Médico de Familia No. 16. Policlínico “Manuel Piti Fajardo". Rev Med Electrón. 2019;41(3):655668.

13. Vila-Candel R, Soriano-Vidal FJ, Murillo Llorente, M, Pérez-Bermejo M, Castro-Sánchez $\mathrm{H}$. Mantenimiento de la lactancia materna exclusiva a los3 meses posparto: experiencia en un departamento desalud de la Comunidad Valenciana. Aten. Primaria. 2019; 51(2):91-98.

14. Rocha KI, Cavalcanti AA. Trabalho feminino, políticas familiares e discursos pró-aleitamento materno: avanços e desafios à equidade de gênero. Saúde debate. 2016; 40(110):208-223. 
15. Baptista SS, Alves VH, Souza RMP, Rodrigues DP, Cruz AFN, Branco MBLR. Manejo clínico da amamentação: atuação do enfermeiro na unidade de terapia intensiva neonatal. Rev Enferm. UFSM. 2015;5(1):23-31.

16. Machado MCM, Assis KF, Oliveira FCC, Ribeiro AQ, Araújo RMA, Cury AF, et al. Determinants of the exclusive breastfeeding abandonment: psychosocial factors. Rev. Saúde Pública. 2014; 48(6):985-94.

17. Dodt RCM, Joventino ES, Aquino PS, Almeida PC, Ximenes LB. An experimental study of an educational intervention to promote maternal self-efficacy in breastfeeding. Rev. Latino-Am. Enfermagem. 2015; 23(4):725-732.

18. World Health Association. Division of Mental Health. Qualitative Research for Health Programmes. Geneva; 1994.

19. Minayo MCS. O desafio do conhecimento: pesquisa qualitativa em saúde. 13ª ed. São Paulo: Hucitec; 2013.

20. Ministério da Saúde (BR). Secretaria de Atenção à Saúde. Departamento de Atenção Básica. Atenção ao pré-natal de baixo risco, $\mathrm{n}^{\circ} 32$. Brasília: Ministério da Saúde, 2013.

21. Duarte EF, Santo CSE, Couto MGC, Andrade VLFS, Matos RCP, Santos El. Estratégia utilizada por enfermeiros na promoção do aleitamento materno no puerpério imediato. Rev Cuid. 2013; 4(1):523-530.

22. Caminha MFC, Cruz RSBLC, Acioly VMC, Nascimento RR, Azevedo PTACC, Lira PIC, et al. Fatores de risco para a não amamentação: um estudo caso-controle. Rev. Bras. Saúde Mater Infant . 2015; 15(2):193-199.

23. Lima MML, Silva TKR, Tsupal PA, Melhem ARF, Brecailo MK, Santos EF. A influência de crenças e tabus alimentares na amamentação. O Mundo da Saúde. 2016; 40(2):221-229.
24. Gomes MRT, Silva LT, Salamoni RM. Investigação dos tabus e crenças alimentares em gestantes de nutrizes do hospital regional de Mato Grosso do Sul-Rosa Pedrossian. Ensaios e Ciência: Ciências Agrárias, Biológicas e da Saúde. 2011;15(6):121-133.

25. Senado Federal (BR). Orientações Nutricionais: da gestação à primeira infância. Brasília: Senado Federal, 2015.

26. Ferreira GR, D'Artibale EF, Bercini LO. Influência da prorrogação da licença maternidade para seis meses na duração do aleitamento materno exclusivo. Rev. Min. Enferm. 2013; 17(2):162-168.

27. Schincaglia RM, Oliveira AC, Sousa LM, Martins KA Práticas alimentares e fatores associados à introdução precoce da alimentação complementar entre crianças menores de seis meses na região noroeste de Goiânia. Epidemiol Serv Saúde. 2015; 24(3): 465-474.

28. Dallazen C, Silva AS, Gonçalves VSS, Nilson EAF, Crispim SP, Lang RMF, et al. Introdução de alimentos não recomendados no primeiro ano de vida e fatores associados em crianças de baixo nível socioeconômico. Cad Saúde Pública. 2018;34(2):e00202816.

29. Martins CA, Abreu WJCP, Figueiredo MCAB. O sofrimento do regresso ao trabalho após a licença parental. Revista Portuguesa de Enfermagem de Saúde Mental. 2015; (spe2):69-77.

30. Rimes KA, Oliveira MIC, Boccolini CS. Maternity leave and exclusive breastfeeding. Rev Saúde Pública. 2019; 53:10.

\section{CORRESPONDÊNCIA}

Albertina Antonielly Sydney de Sousa

Avenida Padre Ibiapina, 1359

Jacarecanga. Fortaleza, Ceará, Brasil.

CEP: 60010-690

E-mail: albertina_sousa@hotmail.com 